\title{
21
}

\section{Modeling Impervious Area Disconnection with SWMM}

\section{William C. Lucas}

Substantial reductions in runoff volume can be obtained with designs integrated to disconnect runoff, especially when combined with measures to improve soil infiltration. The effect of impervious area disconnection was modeled on an office and commercial complex with $67 \%$ impervious cover. The perimeter of the site was graded as a gently sloping biofiltration swale. Flush curbs provided sheet flow conditions to the shallow sides of the swales. Runoff from office building roofs flowed toward lawn inlets under sheet flow and runoff from the commercial building roof discharged directly into the bottom of the swales. These swales, with shallow side slopes and flat bottoms, were designed to provide as much wetted area as possible.

PCSWMM was used to compare three different scenarios:

1. Full1: Full disconnection with a $K_{\text {sat }}$ of $2.54 \mathrm{~cm} / \mathrm{h}(1.0 \mathrm{in} . / \mathrm{h})$ (improved soils);

2. Full1/4: Compared to full disconnection with a $K_{\text {sat }}$ of 0.64 $\mathrm{cm} / \mathrm{h}(0.25 \mathrm{in} . / \mathrm{h})$ (typical soils found in turf management); and

3. None1: No disconnection with a $K_{\text {sat }}$ of $2.54 \mathrm{~cm} / \mathrm{h}(1.0 \mathrm{in} . / \mathrm{h})$ (i.e. direct connection of roof leaders and parking lots to storm drains).

The following results were obtained for the 2005 design year:

Table 21.02005 design year simulation results.

\begin{tabular}{lccc}
\hline \multicolumn{1}{c}{ Disconnection Scenario: } & None1 & Full $1 / 4$ & Full1 \\
\hline Soil $K_{\text {sat }}, \mathrm{cm} / \mathrm{h}(\mathrm{in} . / \mathrm{h}):$ & $2.54(1.00)$ & $0.64(0.25)$ & $2.54(1.00)$ \\
Maximum Outflow, $\mathrm{L} / \mathrm{s}\left(\mathrm{f}^{3} / \mathrm{s}\right):$ & $40.57(10.72)$ & $31.57(8.34)$ & $23.04(6.08)$ \\
Mean Outflow, $\mathrm{L} / \mathrm{s}\left(\mathrm{f}^{3} / \mathrm{s}\right):$ & $0.053(0.0139)$ & $0.021(0.0055)$ & $0.008(0.0020)$ \\
Total Outflow, $\mathrm{m}^{3}\left(\mathrm{f}^{3}\right):$ & $12,423(438,700)$ & $4,916(173,600)$ & $1,792(63,300)$ \\
\hline
\end{tabular}

Lucas, W. 2011. "Modeling Impervious Area Disconnection with SWMM." Journal of Water Management Modeling R241-21. doi: 10.14796/JWMM.R241-21.

(C) CHI 2011 www.chijournal.org ISSN: 2292-6062 (Formerly in Cognitive Modeling of Urban Water Systems. ISBN: 978-0-9808853-4-7) 
These effects of disconnection onto improved soils were substantial. Annual runoff volume was reduced by $86 \%$, while the volume of flows exceeding a threshold of $3.50 \mathrm{~L} / \mathrm{s} / \mathrm{ha}\left(0.05 \mathrm{f}^{3} / \mathrm{s} /\right.$ acre $)$ was reduced by $81 \%$. Both the number and duration of exceedances were reduced by $92 \%$. Disconnection also performed well in the unimproved soils. The annual runoff volume was reduced by $60 \%$, while the volume of exceedance over threshold was reduced by $50 \%$. The number of exceedances was reduced by $77 \%$, while the duration was reduced by $71 \%$.

\subsection{Introduction}

A major adverse impact of total impervious area (TIA) is the frequency of bankfull flooding increasing from once every one or two years under natural conditions to many times per year after urbanization (Booth and Jackson, 1997; Moscrip and Montgomery, 1997). This increase in the frequency, magnitude and duration of bankfull flows requires that stream channels expand to provide the transport capacity such flows need.

While TIA has an undoubtedly adverse impact, recent work has shown that it is perhaps even more important how runoff from impervious surfaces is conveyed to streams. If runoff from roofs and parking areas flows over pervious surfaces such as turf, the amount of runoff can be substantially reduced. This conveyance is known as disconnecting impervious area (DIA). Over a $50 \%$ reduction in runoff volumes was observed in roadside swales by Wanielesta and Yousef (1993). A similar reduction in runoff volumes in Texas was observed by Barrett et al. (1997). In the low intensity rainfall patterns of the Pacific northwest, over $80 \%$ of runoff from roadways was infiltrated in the side slopes of the margin strips (Ahearn and Tveten, 2008). Jamil and Davis (2008) also found high reductions in runoff in roadside swales in Maryland. This widely recognized phenomenon underlies low impact development (LID) techniques widely used throughout the nation.

In contrast with DIA runoff responses, runoff from directly connected effective impervious areas (EIA) travels to stream with little or no attenuation, and so has much greater adverse impact for a given impervious area. Conversion of a watershed in western Washington from forested to medium density residential use (EIA at 29\%) was projected to increase the frequency of the $5 \mathrm{y}$ bankfull flood to nearly six times per year (Booth, 1990), nearly a thirty-fold increase in the frequency. Booth and Jackson (1997) note that the threshold for impacts from urbanization occurs at a 10\% EIA, or 20\% TIA, typical of medium density single family homes.

A $10 \%$ EIA threshold seems to correlate well with the $10 \%$ to $15 \%$ TIA threshold for habitat impacts noted for streams in Delaware by Maxted 
(1997). Work in Vermont suggests that an EIA of up to $10 \%$ was tolerated by cohesive stream banks, but the most sensitive streams could only handle up to 3\% EIA before degradation was noted (MacRae, pers. comm.). More recent work by Walsh et al. (2005) also indicates that EIA was the most important determinant of stream biotic impairment. These studies suggested an EIA threshold as low as $2.5 \%$, beyond which streams in Australia showed signs of significant impairment. Recently, Booth et al. (2004) noted that it was the hydraulic regime that mattered most, not just the percentage EIA.

It is apparent that measures to reduce EIA are most important, and disconnection is fundamental for such measures. Typically, disconnection is accomplished by provision of stormwater control measures (SCMs) such as bioretention or infiltration facilities. These are engineered structures that provide detention and infiltration through improved media and stone reservoirs. In distinct contrast, dispersed SCMs such as filter strips and swales are typically considered to be much less effective, presumably due to their infiltration response being compromised by compaction and disturbance. However, disconnection in filter strips (Munoz-Carpena et al., 1993) has been documented by the observations of Abu-Zreig et al. (2001). Likewise, infiltration into swales has been explicitly modeled in the Delaware urban runoff management model (DURMM) model (Lucas, 2004a), and applied on large scales (Lucas 2007).

While disconnection is typically applied at the lot level where impervious cover is in the range $25 \%$ to $35 \%$, TIA percentage often approaches $95 \%$ in urban settings. However, there are many urban and suburban settings that have TIA below $70 \%$. Given integrated design with measures to improve soil infiltration, substantial reductions in runoff volumes can be obtained from disconnecting runoff with even relatively small receiving areas. Improving soils with deep tillage and incorporation of compost has been extensively documented in the agricultural literature. Pitt et al. (1999) has documented how compost improved infiltration rates, a finding that has been replicated in roadside settings by Ahearn et al. (2008). Pitt (2010) projected that annual reductions due to roof disconnection in Kansas City could exceed $90 \%$. Thus the combination of disconnection and soil amendments has considerable promise as a method to improve the performance of green infrastructure SCMs.

\subsection{Methods}

This chapter presents a modeling analysis of a synthetic commercial and office site located in the mid-Atlantic region. This was the same site that was evaluated in the DURMM User's Manual (Lucas 2004b). Shown in Figure 
21.1, the synthetic office/commercial complex occupied 4.91 acres (1.99 ha), of which 3.29 acres (1.33 ha) were impervious, resulting in $67 \%$ impervious cover.

The primary disconnection SCM was the perimeter swale that drains the parking areas of the site. It was graded with a $1 \%$ longitudinal slope, with a bottom width $4 \mathrm{ft}$ (1.22 m), 10:1 inflow side slopes, and 3:1 back slopes. The perimeter parking was defined by flush curbs and bumper blocks at the outside, with standard raised curb at the sidewalks. This provided sheet flow conditions into the gently sloping (10:1 horizontal: vertical) sides of the swales.

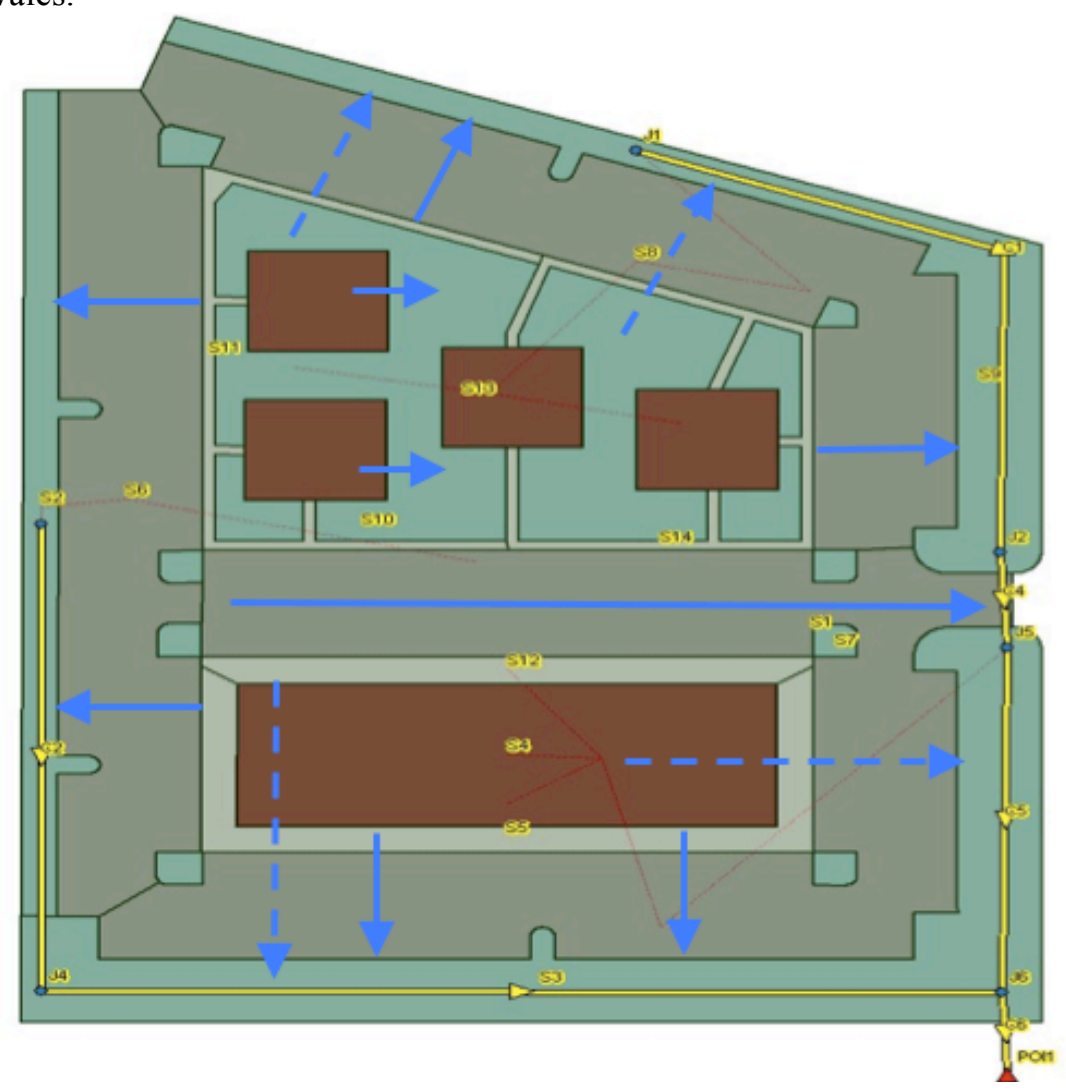

Figure 21.1 Schematic layout of disconnected site.

The central aisles and stalls drained into a trench drain across the entrance. This trench drain conveyed flows from the upper swale into the lower swale segments. The inner sidewalks surrounding the buildings were pitched inward onto the lawn, where flows from the office building roofs also sheet 
flow toward shallow lawn inlets. This effectively used the lawn area as receiving wetted surface for disconnecting roof and sidewalk runoff.

Using small pipes with shallow cover, the lawn inlets discharged directly into the bottom of the swales, as did the runoff from the commercial building roof. These flows are shown as the dashed arrows in Figure 21.1. Given the shallow side slopes and flat bottoms, nearly the entire surface area of the swales was wetted, thus providing as much wetted area as possible. No centralized SCMs such as bioretention or detention structures were used to control peak rates or volumes in this analysis.

The swales were modeled as trapezoidal conduits according to the geometry discussed above. These were placed inside the swale subcatchments so as to represent the time lag that occurs at low flow depths in swales of this geometry (Lucas, 2004). The excerpts of the input files shown in Table 21.1 shows how the swales and subcatchments were modeled. Receiving wetted areas are highlighted in green to show how the subcatchment routing addresses impervious cover.

Table 21.1 Input files used in the Full1 scenario.

\begin{tabular}{|c|c|c|c|c|c|c|c|c|c|c|c|c|}
\hline \multicolumn{13}{|c|}{ SUBAREAS } \\
\hline No. & Name & Outlet & Area & Imperv \% & Width & Slope $\%$ & N-Imperv & N-Perv & S-Imperv & S-Perv & Suction & HydCon \\
\hline S8 & North Parking & S9 & 0.619 & 100 & 449.4 & 1 & 0.013 & 0.10 & 0.05 & & & \\
\hline s9 & North Swale & $\mathrm{J} 1$ & 0.294 & 0 & 853.7 & 10 & & 0.24 & & 0.20 & 2.5 & 1.00 \\
\hline $\mathrm{S} 13$ & Office Roofs & $S 10$ & 0.308 & 100 & 447.3 & 25 & 0.010 & & 0.05 & & & \\
\hline S14 & Office Walks & S10 & 0.063 & 100 & 547.1 & 1 & 0.013 & & 0.05 & & & \\
\hline S11 & Office Walks & S10 & 0.062 & 100 & 540.3 & 1 & 0.013 & & 0.05 & & & \\
\hline $\mathrm{S} 10$ & Office Lawn & S8 & 0.568 & 0 & 380.3 & 10 & & 0.24 & & 0.20 & 2.5 & 1.00 \\
\hline S7 & Landscape Islands & S6 & 0.061 & 0 & 148.2 & 1 & & 0.24 & & 0.20 & 4.0 & 0.50 \\
\hline S6 & East Parking & S2 & 0.579 & 100 & 420.5 & 1 & 0.013 & & 0.05 & & & \\
\hline S2 & East Swale & J3 & 0.168 & 0 & 730.7 & 10 & & 0.24 & & 0.20 & 2.5 & 1.00 \\
\hline S12 & Comm. Walks & S1 & 0.084 & 100 & 367.9 & 1 & 0.013 & & 0.05 & & & \\
\hline S4 & Comm. Roof & S1 & 0.414 & 100 & 450.9 & 1 & 0.024 & & 0.50 & & & \\
\hline S5 & Comm. Walks & S1 & 0.147 & 100 & 638.4 & 1 & 0.013 & & 0.05 & & & \\
\hline S1 & Central Parking & S3 & 1.022 & 100 & 247.4 & 1 & 0.013 & & 0.05 & & & \\
\hline S3 & South Swale & J5 & 0.534 & 0 & 1162.4 & 10 & & 0.24 & & 0.20 & 2.5 & 1.00 \\
\hline COND & & & & & & & & & & & & \\
\hline No. & Name & Inlet & Outlet & Length & Manning & Inlet & Outlet & Shape & Depth & Width & Sides & Sides \\
\hline C1 & North Swale & $\mathrm{J} 1$ & J2 & 333.32 & 0.100 & 108.3 & 105.0 & TRAPEZOIDAL & 2.0 & 4.0 & 10.0 & 3.0 \\
\hline C4 & Trench Drain & J2 & $\mathrm{J} 5$ & 53.73 & 0.013 & 104.5 & 104.3 & RECT_OPEN & 2.5 & 1.0 & 0.0 & 0.0 \\
\hline C5 & West Swale & J5 & J6 & 193.74 & 0.100 & 104.3 & 102.0 & TRAPEZOIDAL & 2.0 & 12.0 & 10.0 & 3.0 \\
\hline C2 & East Swale & J3 & J4 & 496.33 & 0.100 & 109.0 & 105.0 & TRAPEZOIDAL & 2.0 & 4.0 & 10.0 & 3.0 \\
\hline C3 & South Swale & $J 4$ & J6 & 400.27 & 0.100 & 105.0 & 102.0 & TRAPEZOIDAL & 2.0 & 12.0 & 10.0 & 3.0 \\
\hline $\mathrm{C} 6$ & Pipe & J6 & POl1 & 46.49 & 0.013 & 97.0 & 96.5 & CIRCULAR & 1.5 & 0.0 & 0.0 & 0.0 \\
\hline
\end{tabular}

The second part of Table 21.1 shows how the swales (also in green) were modeled as trapezoidal conduits, with their length originating at the midpoint of the swale so as to correspond to the average flow length. They were located within their respective catchments to represent the processes of disconnection upon flow responses of each swale. 
Figure 21.2 displays how different avenues of research suggest how Manning's $n$ varies as a function of VR, the product of hydraulic radius (equal to depth in wide flat channel such as biofiltration swales) and flow velocity. Ree and Palmer (1949) observed how Manning's $n$ increased as VR decreased. These observations were largely based upon emerged flow in which flow depth was higher than vegetation height. In biofiltration swales such as this study, Manning's $n$ varies from as low as 0.060 at deep flow depths to as high as 0.250 when shallow flows are submerged in dense grass.

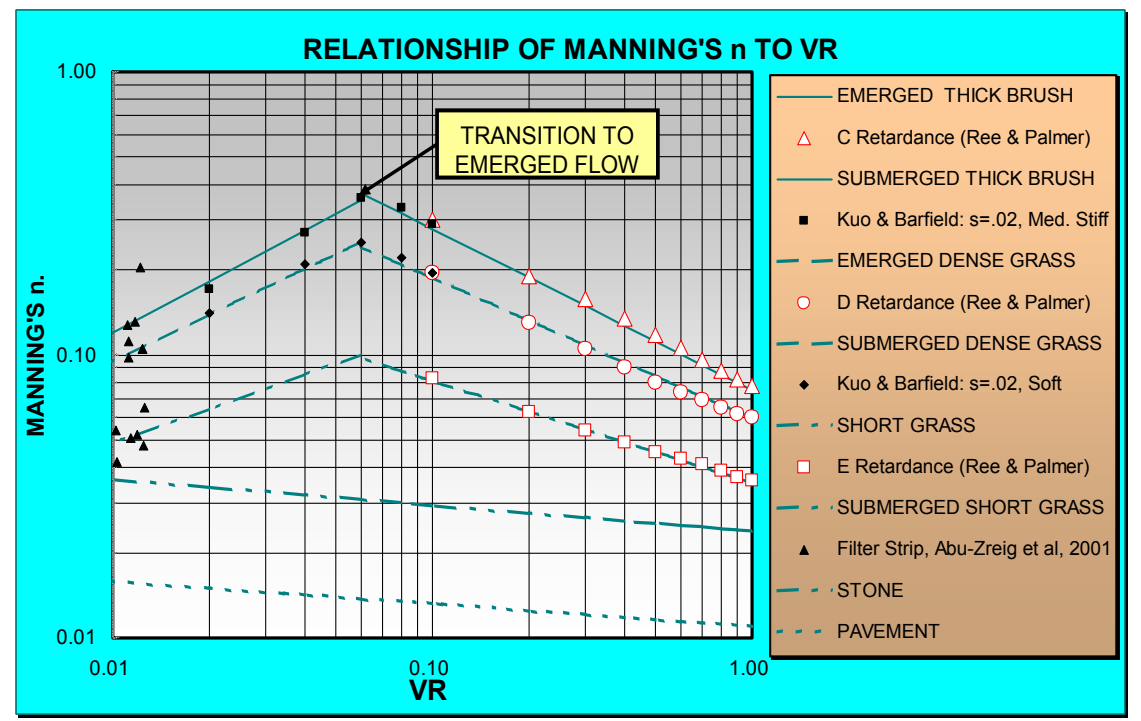

Figure 21.2 Relationship between Manning's $n$ and VR (Lucas, 2004).

Measuring submerged flow responses using synthetic vegetation materials, Kao and Barfield (1978) found that Manning's $n$ for submerged flow decreased as VR decreased. Observations of sheet flow in filter strips by Abu-Zreig et al. (2001) also indicated relatively low $n$ values at very low VR values. These findings are in direct contrast to the results of Kirby et al. (2006), where even higher $n$ values were reported for submerged flow as depth decreased, with Manning's $n$ values approaching 1.00. In either case, Manning's $n$ would remain above 0.100 for submerged flows.

Unfortunately, SWMM 5 cannot vary Manning's $n$ as a function of VR. Therefore, it was allocated a value of 0.100 , a value chosen to be close to that projected for highest flows. In this way, peak flow responses would not be overly retarded. In the normal flow regime under which the swales operated, projected Manning's $n$ values would be substantially higher the vast 
majority of the time, so this simplification understates flow retardance under most conditions.

To model the annual response of this arrangement, PCSWMM was used to compare three different scenarios:

1. Full1: full disconnection with pervious $K_{\text {sat }}$ of $2.54 \mathrm{~cm} / \mathrm{h}$ (1.0 in./h),

2. Full $\frac{1 / 4}{4}$ : full disconnection with pervious $K_{\text {sat }}$ of $0.64 \mathrm{~cm} / \mathrm{h}$ (0.25 in./h)

3. None1: no disconnection with pervious $K_{\text {sat }}$ of $2.54 \mathrm{~cm} / \mathrm{h}$ (1.0 in./h).

The $K_{\text {sat }}$ of $2.54 \mathrm{~cm} / \mathrm{h}(1.0 \mathrm{in} . / \mathrm{h})$ represents soils improved by tillage and compost amendments, while the $K_{\text {sat }}$ of $0.64 \mathrm{~cm} / \mathrm{h}(0.25 \mathrm{in} . / \mathrm{h})$ represents unimproved soils with typical turf management. The Nonel scenario represented direct connection of roof leaders and parking lots to storm drains. For this scenario, the conduits and routing were changed into pipes of the same length and slope, sized to convey the largest flows according to a $10 \mathrm{y}$ NRCS Type II design storm event. Evaporation was applied at the monthly rate for Philadelphia shown in Table 21.2:

Table 21.2 Monthly evaporation rates (in./d).

\begin{tabular}{cccccccccccc}
\hline Jan. & Feb. & Mar. & Apr. & May & June & July & Aug. & Sep. & Oct. & Nov. & Dec. \\
\hline 0.07 & 0.07 & 0.07 & 0.15 & 0.18 & 0.21 & 0.22 & 0.19 & 0.14 & 0.09 & 0.07 & 0.07 \\
\hline
\end{tabular}

Unlike the series of design storm (DS) events used in the DURMM model, this analysis examined the 2005 design year developed by CDM Inc. The 2005 design year was developed to represent the range of rainfall events occurring over 17 y rainfall record. This design year was used to evaluate alternatives for Philadelphia's long term control plan update for combined sewer overflows (CSOs) (PWD, 2009). The continuous simulation (CS) approach using the design year was able to evaluate the cumulative impact of SCMs at a detailed scale with an economy of run time (Lucas, 2010). The three scenarios were run using the 2005 design year, which had a total rainfall of $113.5 \mathrm{~cm}$ (44.7 in.).

\subsection{Results and Discussion}

Table 21.3 presents the subarea and conduit results of the Full1 scenario. The pervious subareas and conduits responsible for disconnection are highlighted. Note how interactions between depression storage, surface roughness and slope of the various contributing impervious areas result in 
quite different evaporation and runoff volumes. This was particularly notable on the commercial roof, which was flat and rough compared to the pitched office roofs. As a result, annual evaporation was over 23 in. $(584.2 \mathrm{~mm})$. Parking and sidewalks have runoff volumes between these two extremes. These interactions between impervious area slope and roughness are important when projecting the EIA runoff implications of different impervious surface types.

Table 21.3 Subarea and conduit results from Full1 scenario.

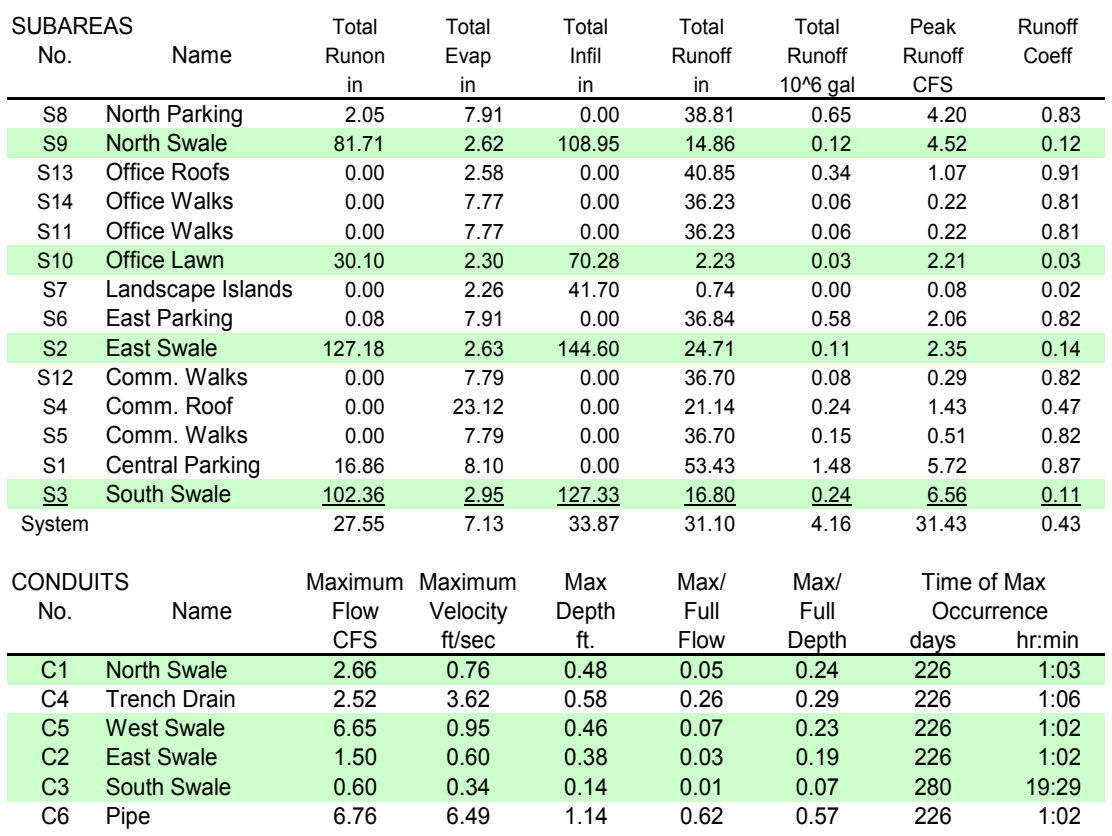

The wetted subareas generated very substantial infiltration volumes due to their very large runon volumes. In the case of the office lawn where the runon depths are less than direct precipitation, there was hardly any runoff (2.2 in., $55.9 \mathrm{~mm}$ ). On the other hand, in the heavily loaded East Swale where runon depths are three times that of precipitation, the runoff volume was an order of magnitude greater $(24.7$ in., $627.4 \mathrm{~mm})$. However, the resulting runoff coefficient was only $14 \%$, demonstrating how effective disconnection can be at even high source area ratios. Table 21.3 also displays the swale depths and velocities when designed for shallow flow conveyance to maximize disconnection. Even during the most extreme event in the year, flow depths in the swales were always less than 6 in. $(152.4 \mathrm{~mm})$ 
As a result, the resulting maximum velocities did not exceed $1.0 \mathrm{fps}(0.305$ $\mathrm{m} / \mathrm{s}$ ).

Figure 21.3 presents the results from the largest event of the design year, the 3.7 in. $(94.0 \mathrm{~mm})$ event of October 9, 2005. As can be seen, the Full11/4 alternative had very little runoff until the peak, which was then surprisingly larger than the None1 scenario. This reflects the interaction between reduced infiltration due to saturated conditions by the time of peak combined with the differing conveyance timing. However, there was a $25 \%$ reduction in volumes. On the other hand, the Full1 alternative provided 59\% reduction in volumes, as well as $11 \%$ reduction in peak flows.

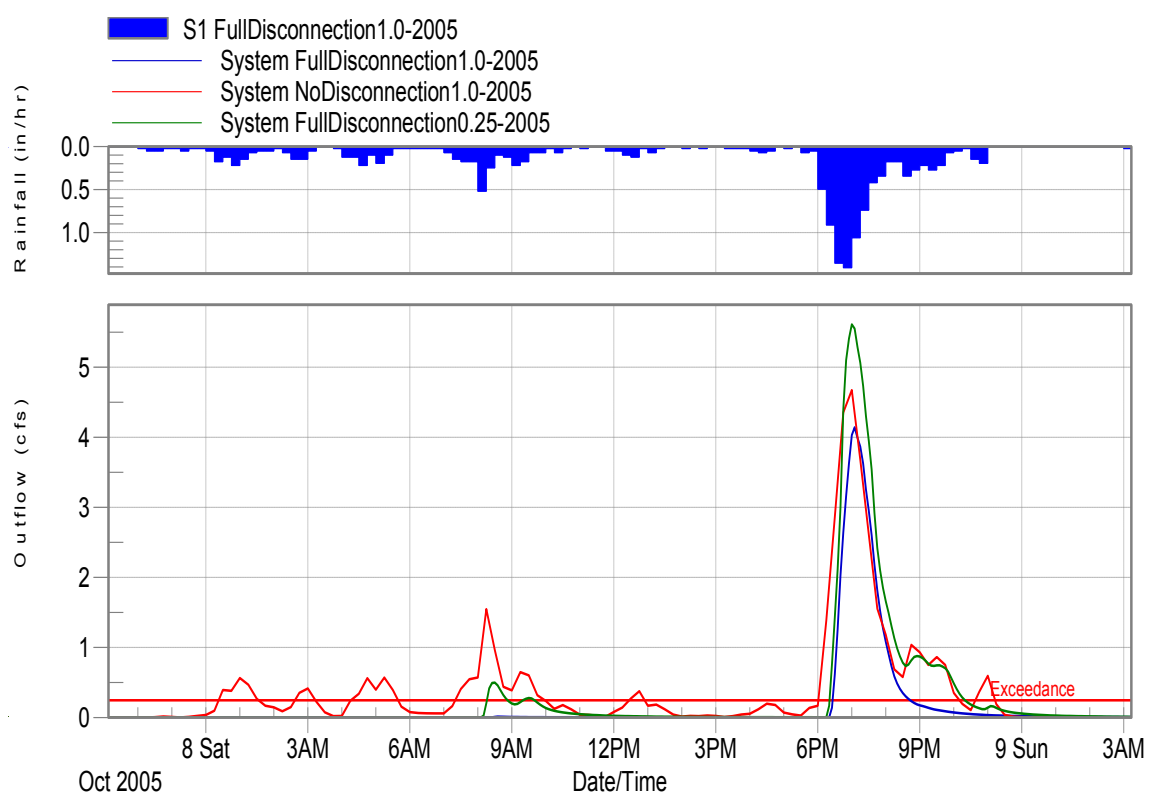

Figure 21.3 The largest event in the design year (2005 10 09).

Figure 21.4 presents the results from the $1.2 \mathrm{in} .(30.5 \mathrm{~mm})$ rainfall event of August 15, 2005, an intense half hour event. Compared to None1, there was a lag with disconnected scenarios before runoff occurred, while the recession limb of the hydrograph extended due to slower conveyance velocities. As a result, volumes decreased by only $7 \%$ with the Full $1 / 4$ and by $30 \%$ with the Full1 scenarios. However, the corresponding peak flows were reduced by $23 \%$ and $43 \%$ respectively. The relatively lower volume reduction was due to the high intensity of rainfall overwhelming the capacity of disconnection to infiltrate the resulting runon volumes in such a short period of time. 

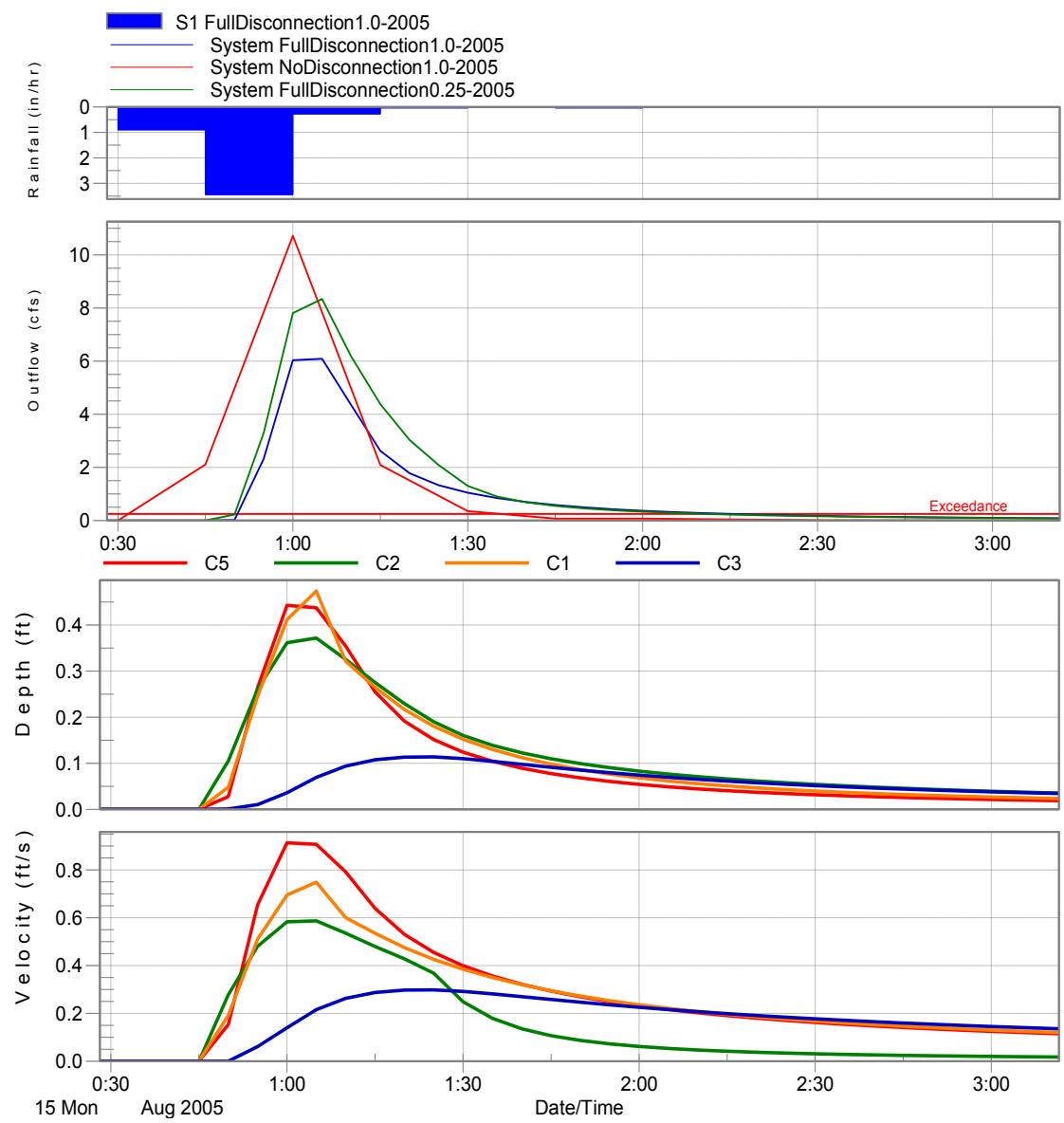

Results:

Maximum Rainfall(in./hr):3.444 Mean Rainfall(in./hr):0.2108 Rainfall(in):1.175

$\begin{array}{lllr}\text { Scenario: } & \text { None1.0 } & \text { Full } 1 / 4 & \text { Full1.0 }\end{array}$

$\begin{array}{llll}\text { Maximum Outflow (cfs): } & 10.72 & 8.342 & 6.089\end{array}$

Mean Outflow (cfs): $\quad 0.7856 \quad 0.7293 \quad 0.5484$

$\begin{array}{llr}\text { Total Outflow }\left(\mathrm{ft}^{3}\right): & 13,920 & 12,920\end{array}$

Figure 21.4 Event of 20050815 from 00:17:57 to 05:13:13.

Flow velocities and depths in biofiltration swales $\mathrm{C} 1-\mathrm{C} 5$ are also shown in Figure 21.4. Biofiltration swale $\mathrm{C} 5$ conveyed the most flows, with a peak flow depth of $0.45 \mathrm{ft}(137.1 \mathrm{~mm})$ at a velocity of $0.9 \mathrm{fps}(0.27 \mathrm{~m} / \mathrm{s})$, resulting in a VR of 0.40. Examination of Figure 21.2 indicates that projected Manning's $n$ for dense grass at this VR would be 0.090 , a value quite close to the 0.100 applied throughout the design year. This suggests that this value of 
0.100 was conservative for all but the briefest of periods for the swale with the highest flow rates. This may have resulted in slightly underestimated peak velocities and flow rates.

This Manning's $n$ value of 0.100 was much lower than actual $n$ values for the low flows that dominate the flow regime. Flow velocities were thus overestimated most of the time, with depths remaining well below 4 inches except at the peak. As a result, flow velocities through the biofiltration swales remained well below $1 \mathrm{fps}(0.30 \mathrm{~m} / \mathrm{s})$, even at peak flows. This is why the disconnected hydrographs were detained compared to the None1 scenario, and thus peak flows were reduced more than the runoff volumes. This illustrates the potential of using vegetative retardance to detain flows without using storage SCMs, even for intense storm events.

In contrast to the preceding extreme events, Figure 21.5 presents the results from the 1.7 in $(43.2 \mathrm{~mm})$ January 14, 2005 event. In this low intensity frontal event, the effect of disconnection was clear. In the Full $1 / 4$ scenario, there was a lag as the wetted area saturates, after which the response was quite similar to the None1 scenario, but without the initial peak. This resulted in a peak flow reduction of $57 \%$, and a volume reduction of $28 \%$.
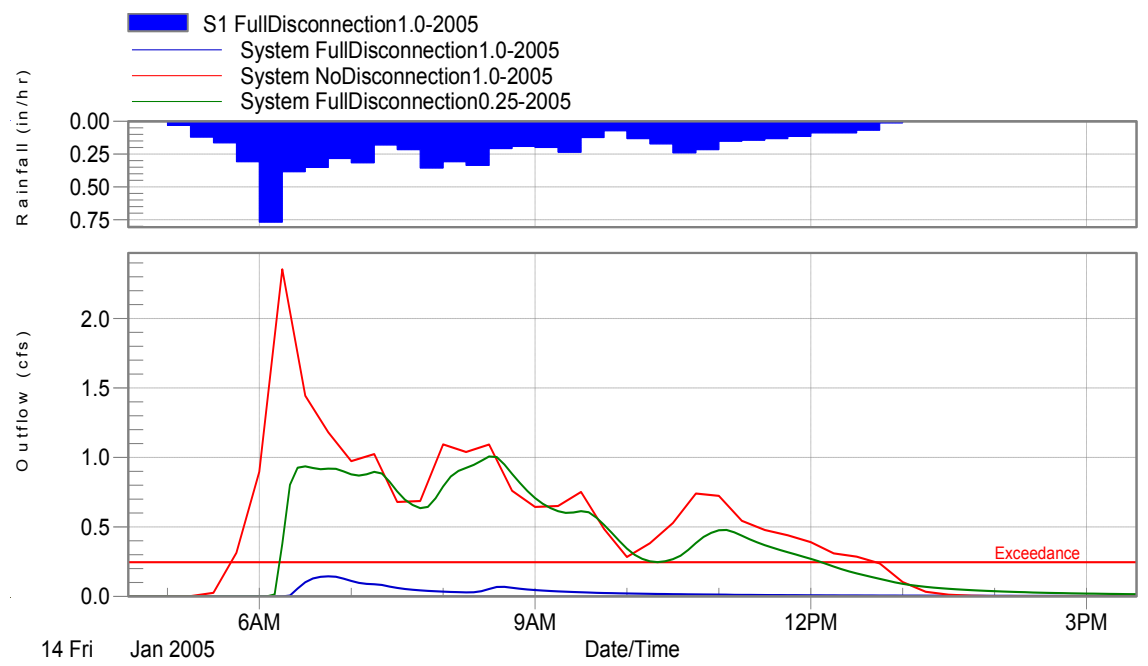

Results:

Scenario:

None 1.0

Full $1 / 4$

Full1.0

Maximum Outflow(cfs):

2.354

0.4089

1.007

0.1445

Mean Outflow(cfs):

19.440

0.2955

0.02022

Total Outflow $\left(\mathrm{ft}^{3}\right)$ :

14,050

961

Figure 21.5 Event of 20050114 from 04:54:19 to 18:06:33. 
In the Full1 scenario, the improved infiltration rate was able to keep up with the rainfall rate, resulting in a peak flow reduction of $94 \%$, and a volume reduction of $95 \%$. Even though this event had more rainfall than that of the August 15 event, by being extended over $9 \mathrm{~h}$ instead only $0.5 \mathrm{~h}$, there was enough time for infiltration from disconnection to be capable of substantially reducing runoff volumes.

Table 21.4 presents the results obtained for the 2005 design year for the three alternatives. The potential threshold to determine CSO exceedances was a runoff rate of $3.50 \mathrm{~L} / \mathrm{s} / \mathrm{ha}\left(0.05 \mathrm{f}^{3} / \mathrm{s} /\right.$ acre $)$. Using the objective function comparison option in PCSWMM, this was shown as the red horizontal line in Figures 21.3 through 21.5. Note how total outflow was substantially reduced as a result of impervious area disconnection processes.

Table 21.42005 design year results, None1, Full1/4 and Full1 scenarios.

\begin{tabular}{lccc}
\hline \multicolumn{1}{c}{ Disconnection Scenario: } & None1 & Full $1 / 4$ & Full1 \\
\hline Soil $K_{\text {sat }}, \mathrm{cm} / \mathrm{h}(\mathrm{in} . / \mathrm{h}):$ & $2.54(1.00)$ & $0.64(0.25)$ & $2.54(1.00)$ \\
Max. Outflow, $\mathrm{L} / \mathrm{s}\left(\mathrm{f}^{3} / \mathrm{s}\right):$ & $40.57(10.72)$ & $31.57(8.34)$ & $23.04(6.08)$ \\
Mean Outflow, $\mathrm{L} / \mathrm{s}\left(\mathrm{f}^{3} / \mathrm{s}\right):$ & $0.053(0.0139)$ & $0.021(0.0055)$ & $0.008(0.0020)$ \\
Total Outflow, $\mathrm{m}^{3}\left(\mathrm{f}^{3}\right):$ & $12,423(438,700)$ & $4,916(173,600)$ & $1,792(63,300)$ \\
Exceedance Volume $\mathrm{m}^{3}\left(\mathrm{f}^{3}\right):$ & $5,847(206,500)$ & $2,917(103,000)$ & $1,127(39,790)$ \\
Exceedance Duration $(\mathrm{hrs}):$ & 131.80 & 38.39 & 10.74 \\
Number of Exceedances: & 133 & 31 & 11 \\
\hline
\end{tabular}

\subsection{Conclusions}

The hydrologic benefits of impervious area disconnection designed to promote extensive sheet flow and conveyance through wide biofiltration swales can be considerable. Using improved soils, the modeling analysis suggests that annual runoff volume would be reduced by $86 \%$, while the volume of exceedance over $0.05 \mathrm{cfs} /$ acre $(35.0 \mathrm{~L} / \mathrm{s} / \mathrm{ha})$ would be reduced by $81 \%$. Both the number and duration of exceedances would be reduced by $92 \%$. Using the same design with unimproved soils, annual runoff volume would be reduced by $60 \%$, with the volume of exceedances reduced by $50 \%$. The number of exceedances would be reduced by $77 \%$, with the duration reduced by $71 \%$.

These results emphasize how an integrated approach to disconnecting impervious runoff can be an effective SCM by itself. In this example, virtually all of the wetted areas are an integral part of the landscaping that would be required in typical high intensity commercial and office settings. Therefore, land exclusively committed for installing this SCM was minimized, even at this high a density. While flood control was not addressed in this 
study, the required detention volume required could easily have been accommodated in the southern and western biofiltration swales. This is largely because the extra detention volume would be that much less due to the reductions in volume from disconnection.

Given its effective potential to simulate pre-development hydrology at relatively low cost, disconnection should be the fundamental basis for LID site design. To accomplish this effectively, these practices must be integrated into the design stage. If done so effectively, the cost for discrete SCMs can then be substantially reduced.

While this may only be a modeling analysis, the bases for the computations are well grounded in terms of underlying physical processes and accepted hydraulic design principles. This analysis supports the use of disconnection as a viable alternative in new projects where careful grading, soil improvement and landscaping can be used to not only disconnect, but also retard overland flows. This key aspect of LID has received remarkably little quantitative analysis. As new versions of SWMM evolve, further refinements for computing the benefits of disconnection will emerge. In particular, routines that explicitly model variations in Manning's $n$ as a function of VR should be developed to better enhance the modeling accuracy.

\section{References}

Abu-Zreig, M., R.P.Rudra, and H.R. Whiteley. (2001). "Validation of a vegetated filter strip model VFS-MOD” Hydrological Processes Vol 15, pp. $729-742$

Ahearn D, and R. Tveten, Legacy LID: (2008) "Stormwater treatment in unimproved embankments along highway shoulders in western Washington" Proceedings of the 2008 International Low Impact Development Conference for Urban Ecosystem and Habitat Protection; Seattle, WA; Nov. 2008.

Barrett, M. E., M. V. Keblin, P. M. Walsh, J. F. Malina, Jr., and R. J. Charbeneau. (1997). Evaluation of the Performance of Permanent Runoff Controls: Summary and Conclusions. Center for Water Res., University of Texas, Austin, TX.

Booth, D. B. (1990). "Stream-Channel Incision Following Drainage-Basin Urbanization." Water Resources Bulletin Vol. 26, No.3, pp. 407-416.

Booth, D. B. and C. R. Jackson. (1997). "Urbanization of Aquatic Systems: Degradation Thresholds, Stormwater Detection, and the Limits of Mitigation." Journal of the American Water Resources Association Vol. 33, No.5, pp. 1077-1089.

Booth, D. B., J. R. Karr, S. Schauman, C. P. Konrad, S. A. Morley, M. G. Larson, \& S. J. Burges. (2004). Reviving urban streams: land use, hydrology, biology, and human behavior. JAWRA 40:1351-1364.

Jamil, N. E. E. and, A. P Davis (2008). "Field Evaluation of Hydrologic and Water Quality Benefits of Grass Swales with Check Dams for Managing Highway Runoff" Proceedings of the 2008 International Low Impact Development Conference for Urban Ecosystem and Habitat Protection; Seattle, WA; USA; 16-19 Nov. 2008.

Kao, D.T.Y. and Barfield, B.J. (1978) "Prediction of Flow Hydraulics for Vegetated Channels" Trans. Am. Soc. Ag. Eng. 21(3):489-494 
Kirby J. T., S. R. Durrans, R. Pitt; and P. D. Johnson. (2006). "Hydraulic Resistance in Grass Swales Designed for Small Flow Conveyance" Journal of Hydraulic Engineering, 131(1): 65-68

Lucas, W.C., (2004a) Green Technology, Delaware's Urban Runoff Management Approach. A Technical Manual for Designing Nonstructural BMPs to Minimize

Stormwater Impacts from Land Development. Delaware Dept of Environmental Resources and Environmental Control (DNREC). Dover, DE, USA

http://www.dnrec.state.de.us/DNREC2000/Divisions/Soil/Stormwater/

New/DURMM_TechnicalManual_01-04.pdf

Lucas, W.C., (2004b) "DURMM: The Delaware Urban Runoff Management Model. A Users Manual for Designing Nonstructural BMPs to Minimize Stormwater Impcts from Land Development." DNREC Dover, DE. (2005). http://www.dnrec.state.de.us/DNREC2000/Divisions/Soil/Stormwater/ New/DURMM_UsersManual_01-04.pdf

Lucas W. C. (2007). "Large-Scale Application of Biofiltration Swale Runoff Management Practices" Water Practice \& Technology (C) IWA Publishing 2007 doi10.2166/wpt. 2007.049

http://www.iwaponline.com/wpt/002/wpt0020049.htm

Lucas, W.C. (2010). Design of Integrated Bioinfiltration-Detention Urban Retrofits with Design Storm and Continuous Simulation Methods. J. Hydrologic Engineering 15(6): 486-498

Maxted, J. R. (1997). "The Use of Percent Impervious Cover to Predict the Ecological Condition of Wadable Nontidal Streams in Delaware." Assessing the Cumulative Impacts of Watershed Development on Aquatic Ecosystems and Water Quality. USEPA, Washington, DC.

Moscrip, A. L., and D. R. Montgomery. (1997). "Urbanization, Flood Frequency, and Salmon Abundance in Puget Lowland Streams." Journal of the American Water Resources Association Vol. 33, No. 6, pp. 1289-1297

Munoz-Carpena, R., J.E. Parsons and J.W. Gilliam, (1993). "Numerical Approach to the Overland Flow Process in Vegetative Filter Strips.” Trans. Am. So. of Ag. Engineers Vol. 36(3), pp. 761-770

Philadelphia Water Department (PWD, 2009) Green City Clean Waters- The City of Philadelphia's Program for Combined Sewer Overflow Control A Long Term Control Plan Update. September 2009 www.phillywatersheds.org/ltcpu/

Pitt, R. E., J. Lantrip, R. Harrison, T.P. O'Connor. (1999). Infiltration Through Disturbed Urban Soils and Compost-Amended Soil Effects on Runoff Quality and Qunatity. EPA/600/R-00/016. USEPA, Washington, DC.

Pitt, R. E. (2010). "Integrating Green Infrastructure into a Combined Sewer Service Area Model" Proceedings, World Environmental and Water Resources Congress 2010: Challenges of Change. page 2950-2963. ASCE.

Ree, W.O. and V.J. Palmer. (1949) Flow of water in channels protected by vegetated lining. US Soil Conservation Service, Technical Bulletin No. 967.

Walsh, C.J, T.D Fletcher and A.R. Ladson. (2005) "Stream restoration in urban catchments through redesigning stormwater systems: looking to the catchment to save the stream" J. N. Am. Benthol. Soc., 2005, 24(3):690-705

Wanielesta, M.P. and Y.A. Yousef.(1993) Stormwater Management. John Wiley \& Sons. New York, NY. 